\title{
Time-resolved luminescent spectroscopy of YAG:Ce single crystal and single crystalline films
}

\author{
Yu. Zorenko ${ }^{\mathrm{a}, *}$, V. Gorbenko ${ }^{\mathrm{a}}$, V. Savchyn ${ }^{\mathrm{a}}, \mathrm{T}$. Vozniak ${ }^{\mathrm{a}}$, V. Puzikov ${ }^{\mathrm{b}}$, A. Danko ${ }^{\mathrm{b}}$, S. Nizhankovski ${ }^{\mathrm{b}}$ \\ ${ }^{a}$ Electronics Department of Ivan Franko National University of Lviv, 107 Gen. Tarnavskyj Str., 79017 Lviv, Ukraine \\ ${ }^{\mathrm{b}}$ Institute for Single Crystals of NAS of Ukraine, 6100 Kharkiv, Ukraine
}

\section{A R T I C L E I N F O}

\section{Article history:}

Received 14 August 2009

Accepted 30 October 2009

\section{Keywords:}

Luminescence

$\mathrm{Ce}^{3+}$ ions

Single crystal and single crystalline films

Antisite defects

\begin{abstract}
A B S T R A C T
The peculiarities of the luminescence and energy transfer from YAG host to the emission centers formed by the $\mathrm{Y}_{\mathrm{Al}}$ antisite defects and $\mathrm{Ce}^{3+}$ ions have been studied in YAG:Ce single crystals, grown from the melt by modified Bridgman method in $\mathrm{Ar}$ and $\mathrm{CO}_{2}+\mathrm{H}_{2}$ atmospheres, and YAG:Ce single crystalline film, grown by liquid phase epitaxy method, using the comparative time-resolved luminescent spectroscopy under excitation by synchrotron radiation in the range of fundamental adsorption of this garnet.
\end{abstract}

(c) 2009 Elsevier Ltd. All rights reserved.

\section{Introduction}

The specific feature of Ce-doped $\mathrm{Y}_{3} \mathrm{Al}_{5} \mathrm{O}_{12}$ (YAG:Ce) single crystal (SC) is large (up to 0.2 at. \%) content of $\mathrm{Y}_{\mathrm{Al}}$ antisite defects (AD) (Ashurov et al., 1977; Lupei et al., 1995). The presence of AD is an inevitable consequence of high-temperature $\left(\sim 2000{ }^{\circ} \mathrm{C}\right)$ growth of SC of garnets from melt by the Czochralski or Bridgman methods (Kuklja, 2000; Stanek et al., 2006). Due to the AD presence, the YAG SC can be considered as a specific type of self-activated phosphors where the $\mathrm{Y}_{\mathrm{Al}} \mathrm{AD}$ as analogues of cation isoelectronic impurities create the emission centers in the UV range and trapping centers as well (Zorenko et al., 2007a; Nikl et al., $2005)$. Due to comparable concentration of both $\mathrm{Ce}^{3+}$ ions and $\mathrm{AD}$ (up to 0.2 at. \%), formation of the Ce-AD coupled centers can occur in (Y,Lu)AG:Ce SC (Zorenko et al., 2007b). Recently the existence of these type centers in LuAG:Ce SC was confirmed by ESR (Laguta et al., 2007). Such centers can be responsible for the main TSL peak at 90 and $150 \mathrm{~K}$ in YAG:Ce and LuAG:Ce SC (Nikl et al., 2005) and large content (up to 75\% in LuAG:Ce SC) of slow components in the $\mathrm{Ce}^{3+}$ emission decay in these scintillators (Zorenko et al., 2007b). Contrary to YAG:Ce SC, due to the low $\left(\sim 1000{ }^{\circ} \mathrm{C}\right)$ temperature of growth by liquid phase epitaxy (LPE) method from melt-solution, the YAG:Ce single crystalline film (SCF) scintillators are free from AD (Zorenko et al., 2007a,b). The YAG:Ce SCF in comparison with SC analogues are characterized by faster decay of $\mathrm{Ce}^{3+}$ emission under high-energy excitation, substantially less content of slow emission

\footnotetext{
* Corresponding author. Tel.: +380 322 394208; fax: +380 322448585.

E-mail address: yurijz@yahoo.com (Y. Zorenko).
}

components and higher energy resolution due to absence of $\mathrm{Y}_{\mathrm{Al}} \mathrm{AD}$ and low concentration of vacancies as emission and trapping centers (Zorenko et al., 2007b; Prusa et al., 2008).

In this work we performed more systematic study of the peculiarities of the intrinsic and $\mathrm{Ce}^{3+-}$ related luminescence and energy transfer from YAG host to the centers formed by the $\mathrm{Y}_{\mathrm{Al}} \mathrm{AD}$ and $\mathrm{Ce}^{3+}$ ions using the comparative time-resolved luminescent spectroscopy of YAG:Ce SC, grown from the melt by different methods, and YAG:Ce SCF, grown by LPE, under excitation by the synchrotron radiation (SR) with an energy in the range of fundamental adsorption of this garnet.

\section{SCF growth and experimental techniques}

Two high-quality samples of YAG:Ce SC were grown in ISC NAS (Kharkiv, Ukraine) by the modified Bridgman method with Mo-crucible in $\mathrm{Ar}$ and reduction $\left(\mathrm{CO}+\mathrm{H}_{2}\right)$ atmosphere at pressure 5-15 Pa (labeled later as YAG: $\mathrm{Ce}(\mathrm{Ar})$ and YAG: $\mathrm{Ce}\left(\mathrm{CO}+\mathrm{H}_{2}\right)$ SCs). The content of $\mathrm{Ce}^{3+}$ ions in these samples was 0.15-0.2 and 0.08-0.1 at. \%, respectively. The YAG:Ce SCF was grown by LPE method from melt-solution based on $\mathrm{PbO}-\mathrm{B}_{2} \mathrm{O}_{3}$ flux in the temperature range $960-1000{ }^{\circ} \mathrm{C}$ on YAG substrates. The concentration of $\mathrm{Ce}^{3+}$ in SCF was in range of $0.03-0.07$ at. \%. The content of lead ions, which also are coming into SCF during the LPE growth, was below $100 \mathrm{ppm}$.

The time-resolved luminescence of YAG:Ce SC and SCF under excitation by SR with an energy of 3.7-12 eV was investigated at 8 and $300 \mathrm{~K}$ at the Superlumi station at HASYLAB, DESY. The emission and excitation spectra were measured both in the 
integral regime and in the time gates $2.2-12.2$ and $111-175$ ns (fast and slow components, respectively) in the limits of SR pulse with a repetition time of 200 ns and duration of 0.127 ns. The luminescence decay kinetics was measured in the time range of $-1.2-200$ ns.

\section{Experimental results and discussion}

The luminescence spectra of YAG: $\mathrm{Ce}(\mathrm{Ar})$ and $\left(\mathrm{CO}-\mathrm{H}_{2}\right)$ SCs at 8 and $300 \mathrm{~K}$ under excitation by SR in the exciton and interband transitions ranges are shown in Fig. 1. Apart from the intensive luminescence in the visible range in the doublet band peaked at 535 and $572 \mathrm{~nm}$ at $300 \mathrm{~K}$ (Fig. 1 ), caused by the $5 \mathrm{~d}^{1} \rightarrow 4 \mathrm{f}^{2}\left({ }^{2} \mathrm{~F}_{5 / 2,7 / 2}\right)$ transitions of $\mathrm{Ce}^{3+}$ ions, the emission spectra of both YAG:Ce SCs at $300 \mathrm{~K}$ consist also of the intrinsic emission bands in the UV range peaked at 305, 372 and $400 \mathrm{~nm}$. By the analogy with the structure of the intrinsic luminescence of undoped YAG SC (Zorenko et al., 2007a), the nature of the mentioned UV bands in YAG:Ce SC can be caused by radiation decay of an exciton localized around $\mathrm{Y}_{\mathrm{Al}} \mathrm{AD}$ ( $\mathrm{LE}(\mathrm{AD})$ centers), recombination luminescence of $\mathrm{Y}_{\mathrm{Al}} \mathrm{AD}$ with formation of excitons bound with these centers, and the luminescence of $\mathrm{F}^{+}$centers, perturbed by the nearest $\mathrm{Y}_{\mathrm{Al}} \mathrm{AD}\left(\mathrm{F}^{+}-\mathrm{AD}\right.$ centers) (Pujats and Springis, 2001). Meanwhile, we can not exclude the influence of $\mathrm{Ce}^{3+}$ ions on formation of the intrinsic emission centers in YAG:Ce SC. In this case the energy structure and luminescent properties of $\mathrm{LE}(\mathrm{AD}), \mathrm{Y}_{\mathrm{Al}}$ and $\mathrm{F}^{+}-\mathrm{AD}$ centers can be somewhat different in comparison with ones in undoped YAG SC.

The luminescence of self-trapped excitons (STE) in the band peaked at $257 \mathrm{~nm}$ is dominating in the spectra of YAG:Ce SC at $8 \mathrm{~K}$ (Fig. 1, curve 5) whereas intensity of the emission of $\mathrm{LE}(\mathrm{AD}), \mathrm{Y}_{\mathrm{Al}}$ and $\mathrm{F}^{+}$-AD centers strongly increases in the RT range (Fig. 1, curves 14). The intensity of intrinsic emission related to $Y_{A l} A D$ centers under high-energy excitation is at least of two times higher in YAG: $\mathrm{Ce}\left(\mathrm{CO}+\mathrm{H}_{2}\right) \mathrm{SC}$ (Fig. 1, curve 2) then that in YAG:Ce (Ar) SC (Fig. 1, curve 1). This result reflects the difference in the technology of crystallization of these SCs, namely in the content of growth atmosphere, resulting in the different concentration of ADs in them.

The emission bands formed by $\mathrm{Y}_{\mathrm{Al}} \mathrm{AD}$ and $\mathrm{F}^{+}-\mathrm{AD}$ centers strongly overlapped with $\mathrm{Ce}^{3+}$ absorption bands peaked at 340 and $460 \mathrm{~nm}$, respectively (Fig. 1). That results in the excitation of $\mathrm{Ce}^{3+}$ luminescence in YAG:Ce SC by the slow emission of AD-related centers under high-energy excitation. Contrary to SC, only $\mathrm{Ce}^{3+}$

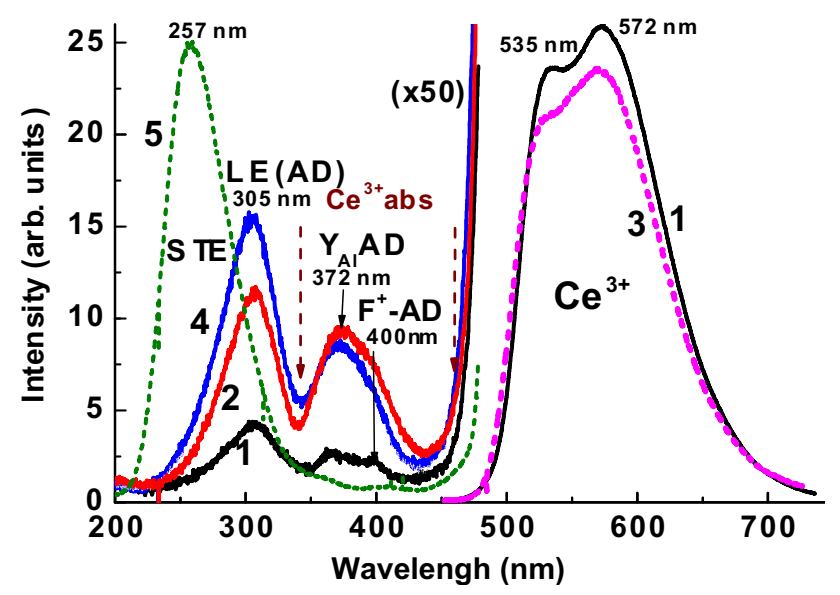

Fig. 1. Emission spectra of YAG:Ce ( $\mathrm{Ar})(1,4,5)$, YAG:Ce $\left(\mathrm{CO}+\mathrm{H}_{2}\right)(2) \mathrm{SCs}$ and YAG:Ce SCF (3) at $300 \mathrm{~K}(1-4)$ and $8 \mathrm{~K}(5)$ under excitation by SR with energies of 13.45 (1, 2, 3), 7.55 (4) and $7.71 \mathrm{eV}(5)$ in the range of interband transition (1-3) and exciton range $(4,5)$.

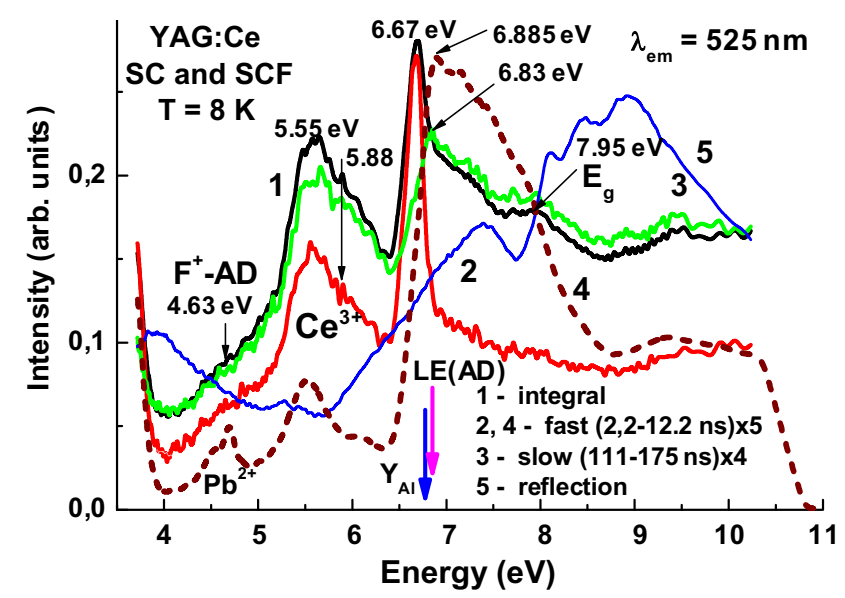

Fig. 2. Excitation spectra of $\mathrm{Ce}^{3+}$ luminescence (1-4) and reflection (5) of YAG:Ce (Ar) SC (1-3) and YAG:Ce SCF (4) at $8 \mathrm{~K}$.

ions emit in YAG:Ce SCF in the RT range under high-energy excitation due do the absence of $A D$ in them (Fig. 2a, curve 3 ). This allows correct determining the fundamental parameters of $\mathrm{Ce}^{3+}$ luminescence in this scintillator.

The excitation spectra of $\mathrm{Ce}^{3+}$ emission in the YAG:Ce SC and SCF (Fig. 2) consist: (i) the band peaked at $7.95 \mathrm{eV}$ related to the onset of YAG interband transition (Zorenko et al., 2007a); (ii) the dominant bands peaked in 6.67-6.885 eV range, corresponding to the formation of exciton bound with the $\mathrm{Ce}^{3+}$ ions; (iii) the band peaked at $5.67 \mathrm{eV}$, related to $4 \mathrm{f}-5 \mathrm{~d}\left({ }^{3} \mathrm{~T}_{2 \mathrm{~g}}\right)$ transition of $\mathrm{Ce}^{3+}$ ions; (iv) the band peaked $4.74 \mathrm{eV}$, caused by the ${ }^{1} \mathrm{~S}_{0} \rightarrow{ }^{3} \mathrm{P}_{1}$ transition of $\mathrm{Pb}^{2+}$ flux dopant in the SCF (Scott and Page, 1977). Due to $\mathrm{Y}_{\mathrm{Al}}$ AD presence and formation of $\mathrm{Ce}-\mathrm{AD}$ coupled centers, the excitation spectra of $\mathrm{Ce}^{3+}$ luminescence in YAG:Ce SC (Fig. 2, curves 1, 2) shown the substantial difference in the shape in the exciton range in comparison with ones for SCF (curves 3). The existence of such $\mathrm{Ce}-\mathrm{AD}$ coupled centers in YAG:Ce SC is also confirmed by the different values of the energy of formation of excitons bound with $\mathrm{Ce}^{3+}$ ions in YAG:Ce SC (6.67 eV) and SCF (6.885 eV) at $8 \mathrm{~K}$ (Fig. 2, curves 2 and 4, respectively). The location of the excitation bands of the $\mathrm{Ce}^{3+}$ emission in YAG:Ce SC, especially of slow components of the emission (Fig. 2, curves 3 ), is close to the position of the excitation bands of the $\mathrm{Y}_{\mathrm{Al}} \mathrm{AD}$ and $\mathrm{LE}(\mathrm{AD})$ luminescence (show in Fig. 2 by arrows); i.e., the centers formed $\mathrm{Y}_{\mathrm{Al}} \mathrm{AD}$ are strongly involved in the excitation of $\mathrm{Ce}^{3+}$ luminescence in YAG:Ce SC.

Another characteristic feature of the excitation spectra of the $\mathrm{Ce}^{3+}$ luminescence in YAG:Ce SC in comparison with ones for SCF analogues is existence excitation band peaked at $4.63 \mathrm{eV}$ which overlapped with low-energy wings of the excitation bands peaked at 5.55 and $5.88 \mathrm{eV}$ at $8 \mathrm{~K}$ caused by the $4 \mathrm{f}-5 \mathrm{~d}\left({ }^{3} \mathrm{~T}_{2 \mathrm{~g}}\right)$ transitions of $\mathrm{Ce}^{3+}$ ions. Most probably, this excitation bands corresponds to excitation of the emission of $\mathrm{F}^{+}-\mathrm{AD}$ center because excitation bands of the luminescence of $\mathrm{F}^{+}$centers in undoped YAG SC are located just in the same range (Zorenko et al., 2004). Thus, the $\mathrm{F}^{+}$ $\mathrm{AD}$ centers can be also involved in excitation of the $\mathrm{Ce}^{3+}$ luminescence in YAG:Ce SC.

The significant participation of $\mathrm{LE}(\mathrm{AD}), \mathrm{Y}_{\mathrm{Al}} \mathrm{AD}$ and $\mathrm{F}^{+}-\mathrm{AD}$ centers in the excitation of the $\mathrm{Ce}^{3+}$ luminescence in YAG:Ce SC are also confirmed by the decay kinetics of the $\mathrm{Ce}^{3+}$ emission under excitation in the exciton and interband transitions ranges in comparison with ones for SCF analogue (Fig. 3). Under excitation by SR with energy of $3.71 \mathrm{eV}$ in the $5 \mathrm{~d}^{1} \mathrm{Ce}^{3+}$ absorption bands the decay times of the $\mathrm{Ce}^{3+}$ luminescence in YAG:Ce SCF (70.7 ns) and both SCs (79-80 ns) is somewhat different (Fig. 3, curves 1-3) mainly due to the difference in $\mathrm{Ce}^{3+}$ content. At the same, due to 


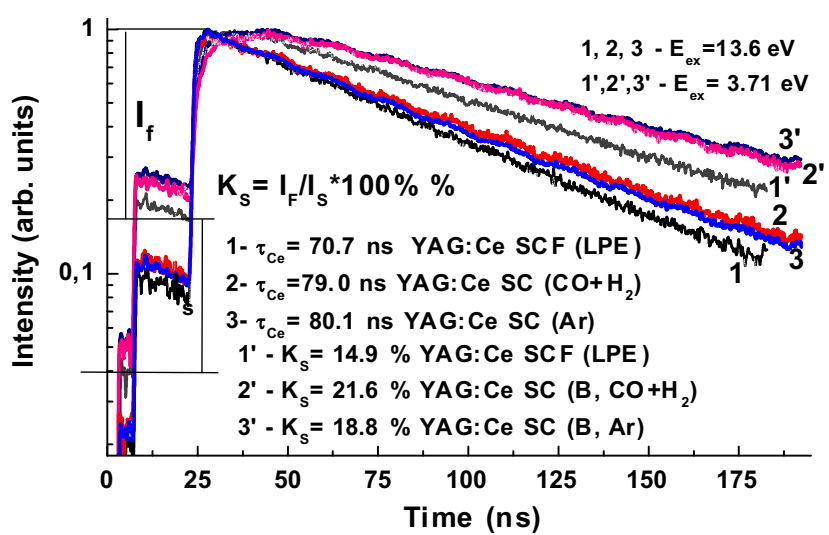

Fig. 3. Decay kinetics of $\mathrm{Ce}^{3+}$ emission in YAG:Ce (Ar) SC (2, $\left.2^{\prime}\right)$, YAG: $\mathrm{Ce}\left(\mathrm{CO}+\mathrm{H}_{2}\right) \mathrm{SC}$ $\left(3,3^{\prime}\right)$ and YAG:Ce SCF $\left(1,1^{\prime}\right)$ at $300 \mathrm{~K}$ under excitation by SR with energies of $3.71 \mathrm{eV}$ $(1-3)$ in $\mathrm{Ce}^{3+}$ absorption band and $13.6 \mathrm{eV}\left(1^{\prime}-3^{\prime}\right)$ in the range of interband transition. The decay time of $\mathrm{Ce}^{3+}$ luminescence under $3.71 \mathrm{eV}$-excitation and content of slow components in $\mathrm{Ce}^{3+}$ emission under high-energy excitation (13.6 eV) in YAG:Ce SCs and SCF are presented.

excitation of the $\mathrm{Ce}^{3+}$ luminescence in YAG:Ce SC by emission of $\mathrm{LE}(\mathrm{AD}), \mathrm{Y}_{\mathrm{Al}}$ and $\mathrm{F}^{+}-\mathrm{AD}$ centers (Zorenko et al., 2007a) as well as the temporal localization of charge carriers on these centers in the RT range (Nikl et al., 2005), the decay kinetics of the $\mathrm{Ce}^{3+}$ luminescence in both SCs is notable slower (Fig. 3, curve $2^{\prime}$ and $3^{\prime}$ ) than that in SCF analogue (Fig. 3, curve $1^{\prime}$ ). Namely, under high-energy excitation (13.6 eV) the mean decay time of YAG:Ce SCF and YAG:Ce (Ar) and $\left(\mathrm{CO}-\mathrm{H}_{2}\right) \mathrm{SC}$ is equal to $95,108.1$ and $113 \mathrm{~ns}$, respectively (Fig. 3).

We estimate the content of slow components in the scintillation decay of the YAG:Ce SC and SCF, using the ratio between intensity $I_{\mathrm{S}}$ of the decay components, which are slower than the repetition frequency of SR (200 ns), and decay amplitude $I_{t}$ of the rising part of scintillation pulse as $K_{\mathrm{s}}=\left[I_{\mathrm{S}} / I_{\mathrm{t}}\right] * 100 \%$ (Fig. 3). The content of slow components is notable larger in YAG: $\mathrm{Ce}(\mathrm{Ar})$ and $\left(\mathrm{CO}+\mathrm{H}_{2}\right) \mathrm{SCs}$ (18.8\% and $21.6 \%$, respectively) in comparison with that in YAG:Ce SCF (14.9\%) (Fig. 3). The main reason for a slowing-down of the decay of $\mathrm{Ce}^{3+}$ luminescence and an increase of the amount of slow emission components is large content of $\mathrm{Y}_{\mathrm{Al}} \mathrm{AD}$ and $\mathrm{F}^{+}-\mathrm{AD}$ centers, in YAG:Ce SC, grown by the modified Bridgman methods in $\mathrm{Ar}$ and reducing $\mathrm{CO}_{2}+\mathrm{H}_{2}$ atmosphere in comparison with the condition of low-temperature crystallization of SCF from the MS in air.

Concluding, we studied in this work the intrinsic and $\mathrm{Ce}^{3+}{ }_{-}$ related luminescence and energy transfer from YAG host to the centers formed by the $\mathrm{Y}_{\mathrm{Al}} \mathrm{AD}$ and $\mathrm{Ce}^{3+}$ ions using the time-resolved luminescent spectroscopy of YAG:Ce SC, grown by different methods from the melt, and YAG:Ce SCF, grown by LPE method, under excitation by the synchrotron radiation in the range of fundamental adsorption of this garnet.

Apart from the $\mathrm{Ce}^{3+}$ luminescence in the visible range, the emission spectra of YAG:Ce SC at $300 \mathrm{~K}$ consist also of the intrinsic emission in the UV range caused by formation of an exciton localized around $\mathrm{Y}_{\mathrm{Al}}$ antisite defects (ADs) (LE(AD) centers)), recombination luminescence of $\mathrm{Y}_{\mathrm{Al}} \mathrm{ADs}$ and the luminescence of $\mathrm{F}^{+}$ centers, perturbed by the nearest $\mathrm{Y}_{\mathrm{Al}} \mathrm{AD}$ ( $\mathrm{F}^{+}-\mathrm{AD}$ centers). Due to comparable concentration of both $\mathrm{Ce}^{3+}$ ions (0.1-0.25 at. \%) and $\mathrm{AD}$ (up to 0.2 at. \%), formation of the $\mathrm{Ce}-\mathrm{AD}$ coupled centers occur in YAG:Ce SC. The existence of Ce-AD coupled centers is supported by the different values of the energy of formation of excitons bound with Ce ion in YAG:Ce SC (6.67 eV) and SCF (6.885 eV) at $8 \mathrm{~K}$.

We show that the centers formed $\mathrm{Y}_{\mathrm{Al}} \mathrm{AD}$ centers are strongly involved in the excitation of $\mathrm{Ce}^{3+}$ luminescence in YAG:Ce SC due to reabsorption of $\mathrm{AD}$-related emission by the $\mathrm{Ce}^{3+}$ absorption bands and temporal localization of charge carries at $\mathrm{AD}$ and $\mathrm{Ce}^{3+}$ ions as trapping centers. We show the correlating between the content of slow components in the scintillation decay of the studied YAG:Ce SC and SCF and concentration of $\mathrm{Y}_{\mathrm{Al}}$ ADs. Namely, for YAG:Ce SCs, grown by modified Bridgman methods in $\mathrm{Ar}$ and reduction $\mathrm{CO}+\mathrm{H}_{2}$ atmosphere the content of slow component in the decay of $\mathrm{Ce}^{3+}$ emission is somewhat large (18.8 and $21.6 \%$, respectively) in comparison with AD-free YAG:Ce SCF (14.9\%).

Contrary to SC, only $\mathrm{Ce}^{3+}$ luminescence is observed in YAG:Ce SCF in the RT range under high-energy excitation due do the absence of AD-related centers in them. This allows correct determining the fundamental parameters of $\mathrm{Ce}^{3+}$ luminescence in this scintillator, such energy of formation of excitons bound with $\mathrm{Ce}$ ions $(6.885 \mathrm{eV})$ and decay time of emission under high-energy excitation (95 ns).

\section{References}

Ashurov, M., Voronko, Yu., Osiko, V., Solol, A., 1977. Spectroscopic investigation of structural disordering of garnet crystals with rare-earth dopants. Phys. Stat. Sol. (a) 42, 101-110.

Kuklja, M.M., 2000. Defects in yttrium aluminium perovskite and garnet crystals: atomistic study. J. Phys. Condens. Matter 12, 2953-2967.

Laguta, V., Slipenyuk, A.M., Glinchuk, M.D., Bykov, I.P., Zorenko, Y., Nikl, M., Rosa, J., Nejezchleb, K., 2007. Paramagnetic impurity defects in LuAG:Ce thick film scintillators. Radiat. Meas. 42, 835-838.

Lupei, V., Lupei, A., Tiseanu, C., Georgescu, S., Stoicescu, C., Nanan, P.M., 1995. Highresolution optical spectroscopy of YAG: Nd: a test for structural and distribution models. Phys. Rev. B 51, 8-17.

Nikl, M., Mihokova, E., Pejchal, J., Vedda, A., Zorenko, Yu, 2005. The antisite $\mathrm{Lu}_{\mathrm{Al}}$ defect-related trap in $\mathrm{Lu}_{3} \mathrm{Al}_{5} \mathrm{O}_{12}$ :Ce single crystal. Phys. Stat. Sol. (b) 242, R119-R121.

Prusa, P., Cechak, T., Mares, J.A., Nikl, M., Zorenko, Y., Gorbenko, V., Tous, J., Blazek, K., 2008. The $\alpha$-particle excited scintillation response of the liquid phase epitaxy grown LuAG:Ce thin films. Appl. Phys. Lett. 2, 1-3.

Pujats, A., Springis, M., 2001. The F-type centres in YAG crystals. Radiat. Eff. Defects Solids $155,65-69$.

Scott, G.B., Page, J.L., 1977. Pb valence in iron garnets. J. Appl. Phys. 48, 1342-1352.

Stanek, C.R., McClellan, K.J., Levy, M.R., Grimes, R.W., 2006. Extrinsic defect structure of $\mathrm{RE}_{3} \mathrm{Al}_{5} \mathrm{O}_{12}$ garnets. Phys. Stat. Sol. (b) 243, R75-R77.

Zorenko, Yu., Voloshinovskii, A., Konstankevych, I., 2004. Luminescence of $\mathrm{F}^{+}$and $\mathrm{F}$ centers in $\mathrm{YAlO}_{3}$. Opt. Spectrosc. 96, 532-537.

Zorenko, Yu., Voloshinovskii, A., Savchyn, V., Vozniak, T., Nikl, M., Nejezchleb, K., Mikhailin, V., Kolobanov, V., Spassky, D., 2007a. Exciton and antisite defectrelated luminescence in $\mathrm{Lu}_{3} \mathrm{Al}_{5} \mathrm{O}_{12}$ and $\mathrm{Y}_{3} \mathrm{Al}_{5} \mathrm{O}_{12}$ garnets. Phys. Stat. Sol. (b) 244, 2180-2189.

Zorenko, Y., Gorbenko, V., Konstankevych, I., Voznjak, T., Savchyn, V., Nikl, M., Mares, J.A., Nejezchleb, K., Mikhailin, V., Kolobanov, V., Spassky, D., 2007b. Single crystalline film scintillators based on $\mathrm{Ce}$ - and Pr-doped aluminium garnets. Radiat. Meas. 42, 528-532. 